\title{
Identifying the Long-Term Thermal Storage Stability of SBS-Polymer-Modified Asphalt, including Physical Indexes, Rheological Properties, and Micro-Structures Characteristics
}

\author{
Peng Wang *(D), Hong-Rui Wei, Xi-Yin Liu, Rui-Bo Ren and Li-Zhi Wang \\ School of Transportation Engineering, Shandong Jianzhu University, Jinan 250101, China; \\ whr50081858@126.com (H.-R.W.); liuxiyin123@163.com (X.-Y.L.); rrbgq@sdjzu.edu.cn (R.-B.R.); \\ wlz85503@sdjzu.edu.cn (L.-Z.W.) \\ * Correspondence: peng0462@126.com or wangpeng0462@sdjzu.edu.cn; Tel.: +86-18560027486
}

check for updates

Citation: Wang, P.; Wei, H.-R.; Liu,

X.-Y.; Ren, R.-B.; Wang, L.-Z.

Identifying the Long-Term Thermal Storage Stability of

SBS-Polymer-Modified Asphalt,

including Physical Indexes,

Rheological Properties, and

Micro-Structures Characteristics.

Sustainability 2021, 13, 10582.

https://doi.org/10.3390/su131910582

Academic Editors: Joel R.M. Oliveira, Hugo Silva, R. Christopher Williams and Zejiao Dong

Received: 24 August 2021

Accepted: 17 September 2021

Published: 24 September 2021

Publisher's Note: MDPI stays neutral with regard to jurisdictional claims in published maps and institutional affiliations.

Copyright: (C) 2021 by the authors. Licensee MDPI, Basel, Switzerland. This article is an open access article distributed under the terms and conditions of the Creative Commons Attribution (CC BY) license (https:/ / creativecommons.org/licenses/by/ $4.0 /)$.
Abstract: The thermal storage stability of styrene-butadiene-styrene tri-block copolymer modified bitumen (SBSPMB) is the key to avoid performance attenuation during storage and transportation in pavement engineering. However, existing evaluation index softening point difference within $48 \mathrm{~h}\left(\triangle S P_{48}\right)$ cannot effectively distinguish this attenuation of SBSPMB. Thus, conventional physical indexes, rheological properties, and micro-structure characteristics of SBSPMB during a 10-day storage were investigated in this research. Results showed that during long-term thermal storage under $163^{\circ} \mathrm{C}$ for 10 days, penetration, ductility, softening point, recovery rate $(R \%)$, and anti-rutting factor $\left(G^{*} / \sin \delta\right)$ were decayed with storage time increasing. This outcome was ascribed to the phase separation of SBS, which mainly occurred after a 4-day storage. However, $\Delta S P_{48}$ after a 6-day storage met the specification requirements (i.e., below $2.5^{\circ} \mathrm{C}$ ). Thus, the attenuation degree of asphalt performance in field storage was not effectively characterized by $\triangle S P_{48}$ alone. Results from network strength $(I)$ and SBS swelling degree tests revealed that the primary cause was SBS degradation and base asphalt aging. Moreover, conventional indexes, including penetration, ductility, and softening point, were used to build a prediction model for rheological properties after long-term storage using partial least squares regression model, which can effectively predict $I, R, J_{\mathrm{nr}}, G^{*} / \sin \delta$, and SBS amount. Correlation coefficient is above $0.8 . G^{*} / \sin \delta$ and $I$ at the top and bottom storage locations had high coefficient with SBS amount. Thus, phase separation of SBSPMB should be evaluated during thermal storage.

Keywords: polymer-modified asphalt; thermal storage stability; relationship between macro performance and micro structures; partial least squares regression

\section{Introduction}

Styrene-butadiene-styrene tri-block (SBS) polymer-modified bitumen (PMB) (i.e., SBSPMB) has been applied globally in road pavements owing to its superior performance. Compared with polyethylene (PE), styrene butadiene rubber (SBR), and ethylene-vinyl acetate (EVA), SBS can provide outstanding stiffness and elastic recovery characteristics over a wide temperature range to conventional asphalt [1,2]. SBSPMB also serves in porous pavement for sustainability of urban environment $[3,4]$, thus, this binder has dominated the PMB market. However, SBS copolymers are far from perfect. The poor storage stability of SBSPMB remains a crucial but difficult challenge to be addressed.

The poor storage stability of SBSPMB often results from poor compatibility between SBS polymers and bitumen, which is controlled by the different properties of polymers and bitumen, such as density, molecular weight, polarity, and solubility [5]. Poor compatibility leads to phase separation between SBS and asphalt [6-8]. Actually, SBS has a biphasic morphology composed of polystyrene (PS) and polybutadiene (PB), in which rigid PS and flexible PB are the dispersed and continuous phases, respectively $[9,10]$. When a suitable 
amount of SBS is added into asphalt, PB can be swollen by the light components in asphalt but PS is pure without change. The combination of the hardness of PS and softness of PB could form a rubbery supporting network in the asphalt, and increase the anti-rutting, anticracking, and elastic response to the asphalt matrix. The strength of this physical crosslink network comes from intermolecular forces [11]. Thus, it is easily destroyed by heat and oxidation because of the presence of double bonds and hydrogen in the $\alpha$-position $(\alpha-\mathrm{H})$ in PB blocks [12] and loss of the light components of asphalt [5]. Zhu believed that density difference was one of the causes of PMB instability in the gravity field [13]. Consequently, an extensive rule for SBSPMB is that SBS is partially swollen by the light components of bitumen to form a thermodynamically unstable but kinetically stable system. Nevertheless, this kinetically stable system is a type of metastable state in the gravity field. Lastly, phase separation resulted in a worse performance for SBSPMB during thermal storage, which is called segregation in road engineering.

Therefore, segregation is a crucial issue in PMB. Numerous studies have concentrated on preventing the segregation of SBSPMB, including optimizing the production process, grafting modifier, or adding stabilizers. Ali found that the mixing time during the blending process of the polymer and asphalt had a significant influence on the polymer particle distribution [14]. Fu reported that SBS-g-M grafted with vinyl monomer under c-rays irradiation could significantly improve the storage stability of SBS-modified asphalt [15]. Ren adopted SBS latex to avoid the segregation of SBSPMB [16]. Among many technologies, sulfur or polymerized sulfur is a common stabilizer for SBSPMB [17-19]. Sulfur is a chemically coupling polymer and bitumen through sulfide or polysulfide bonds, that leads to polymer molecule crosslinking, and provides considerably stronger interactions to form a stable polymer network compared with the physical ones [5]. Aromatics-rich oil (light components) is also a frequently used way to improve SBS swelling that decreases the segregation of SBSPMB $[20,21]$. Also, there is a side effect of the use of sulfur, as some studies have indicated that there was some element of insoluble sulfur in the vapour produced during the process of mixing and dumping of the asphalt mixture which could have bad effects on the safety of workers, particularly effects on the eyes and skin. Thus, antioxidants [22], nanomaterials [10,23-25], and other functionalization of polymers [24,26] are proposed. Overall, sulfur stabilizers remain the most widely used.

Extensive effort has been focused on the effective evaluation indexes on segregation. This method aims to extensively use closed aluminum toothpaste tubes at $163{ }^{\circ} \mathrm{C}$ to mimic the storage and transportation conditions of SBSPMB [19]. The softening point difference after a 48 -h storage period $\left(\triangle S P_{48}\right)$ of SBSPMB in the top and bottom $1 / 3$ part of the tube is the most popular control index used to evaluate PMB stability. However, this conventional index is insufficient to identify whether or not PMB is stable, particularly for long-term storage. Thus, Zhu introduced a phase-field method to capture the phase separation of SBSPMB [27]. Liang used fluorescence microscopy (FM) combined with the phase field model to describe the SBS-phase distribution during storage [28]. Singh reported the rheological property changes with storage time [29]. Typically, each asphalt tank truck can load approximately 40 tons of asphalt. However, using a truck of asphalt in pavement engineering in a short time is difficult, particularly during bad weather. Therefore, before asphalt mixture mixing, SBSPMB is exposed to elevated temperatures $\left(100-180{ }^{\circ} \mathrm{C}\right)$ in closed metal containers with vents for a long time [30], occasionally for over a week. However, only a few studies have focused on the performance decay of SBSPMB during long-term thermal storage.

This study aims to identify the macro-performance and micro-characteristics attenuation of SBSPMB during long-term storage to control the quality of SBSPMB in the field. Segregation test was conducted to simulate the thermal storage procedure. First, macroperformance was used to determine the conventional and rheological index attenuations as storage time increases, which were obtained from softening point, multi-stress creep recovery, and small strain oscillatory rheological tests. Second, micro-characteristics of the SBS degradation during storage were investigated via attenuated total reflection infrared spec- 
troscopy (ATR-FTIR), FM, and atomic force microscopy (AFM). Lastly, a grey relation was used to determine the relationship between macro-performance and micro-characteristics, and the partial least squares (PLS) method was used to predict rheological properties based on conventional physical indexes. This research will be beneficial in markedly improving our understanding of the durability of PMB and controlling its quality in the field.

\section{Materials and Methods}

\subsection{Materials}

The grade of base asphalt used is Penetration $70 \mathrm{dmm}$ (marked as A70\#). A linear type SBS with molecular weight $110,000 \mathrm{~g} / \mathrm{mol}$ was used in this research. Commercial sulfur stabilizers were used as asphalt stabilizers. The properties and characteristics of base asphalt and SBS modifier are listed in Table 1.

Table 1. Properties and characteristics of base asphalt and SBS modifiers.

\begin{tabular}{|c|c|c|c|c|c|}
\hline \multirow{2}{*}{ Base Asphalt } & \multicolumn{2}{|c|}{ Ductility @ $10^{\circ} \mathrm{C} / \mathrm{cm}$} & $\begin{array}{l}\text { Softening } \\
\text { Point } /{ }^{\circ} \mathrm{C}\end{array}$ & \multicolumn{2}{|c|}{ Penetration @ $25^{\circ} \mathrm{C} / \mathrm{dmm}$} \\
\hline & \multicolumn{2}{|c|}{38} & 49 & \multicolumn{2}{|r|}{70} \\
\hline \multirow{2}{*}{$\begin{array}{c}\text { SBS } \\
\text { Modifiers }\end{array}$} & Type & Size & $\begin{array}{l}\text { Polybutadiene } \\
\text { Content } \%\end{array}$ & $\begin{array}{l}\text { Polystyrene } \\
\text { Content } / \%\end{array}$ & $\begin{array}{c}\text { Molecular } \\
\text { Weight } / \mathrm{g} \cdot \mathrm{mol}^{-1}\end{array}$ \\
\hline & Linear & 20 mesh & 70 & 30 & 110,000 \\
\hline
\end{tabular}

The SBSPMB was prepared using a high-shear mixer (WeiYu Machine Co., Ltd., Shanghai, China). Base asphalt was heated at $160^{\circ} \mathrm{C}$ for improved flow. SBS polymers (4.5 wt.\% by asphalt weight) were added to the asphalt at $175{ }^{\circ} \mathrm{C}$ for $30 \mathrm{~min}$ at a fixed rotation speed for 3000-3500 r/min. Thereafter, asphalt stabilizer $(0.25 \mathrm{wt}$. \% by asphalt weight) was added into the mixtures at $180{ }^{\circ} \mathrm{C}$ for $5 \mathrm{~min}$. Finally, it was polymer swelling at low temperature and shearing speed to prevent base asphalt aging, and the swelling conditions were $165^{\circ} \mathrm{C}, 60 \mathrm{~min}$ at a fixed rotation speed of $2500 \mathrm{r} / \mathrm{min}$.

\subsection{Methods}

The entire experimental design is summarized in Figure 1. Long-term thermal storage samples were obtained from segregation test in accordance with ASTM D 5975. The storage time was $0,2,4,6,8$, and 10 days.

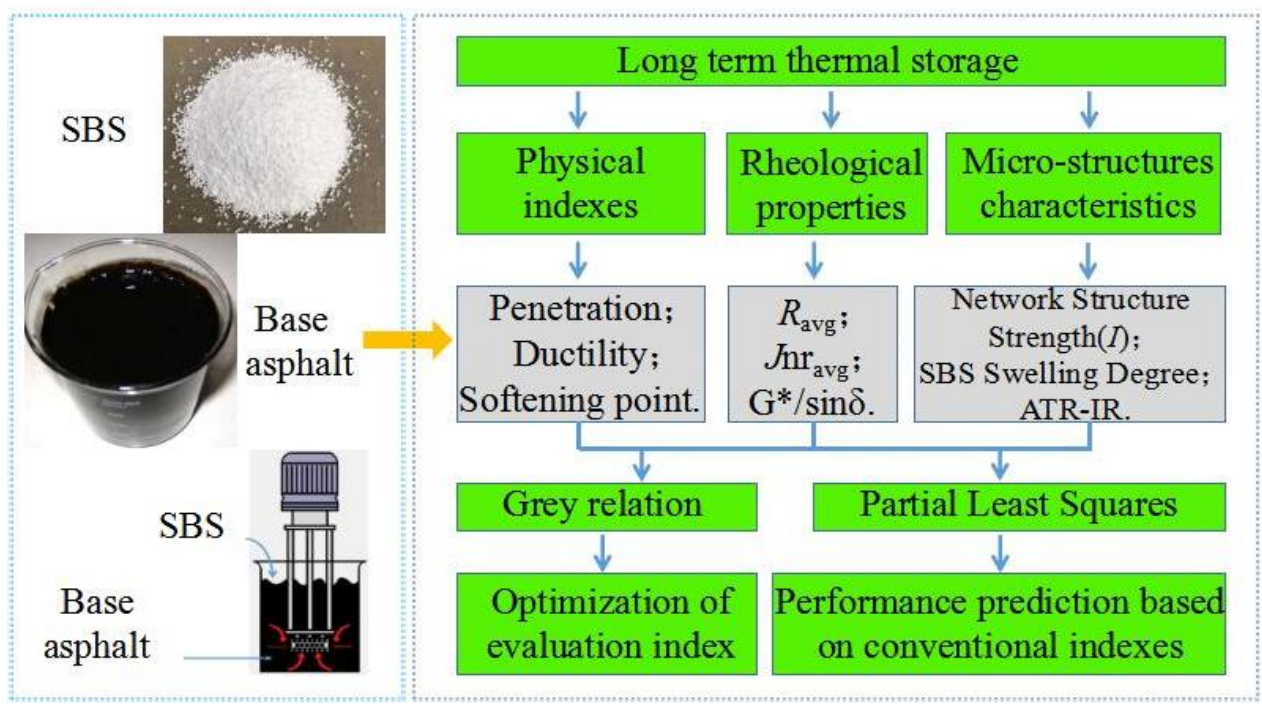

Figure 1. Experimental design flowchart. 
This figure shows that storage samples were obtained from segregation tests in accordance with ASTM D 5975. However, the storage time was not only $48 \mathrm{~h}$. Macroperformance testing of SBSPMB included conventional physical and rheological indexes. Conventional physical indexes were obtained by softening point, penetration at $25{ }^{\circ} \mathrm{C}$, and ductility at $5{ }^{\circ} \mathrm{C}$, which were in accordance with ASTM D2398, ASTM D 5, and ASTM D 113, respectively. Softening point difference $\left(\Delta S P_{48}\right)$ was obtained from ASTM D5976. Rheological indexes were obtained from a Multiple Stress Creep Recovery Test (MSCR) and small strain oscillatory rheological test. MSCR was used to determine irrecoverable compliance $(\mathrm{Jnr})$, recovery rate $(R \%)$, and accumulative strain in accordance with ASTM D7405-10a. Small strain oscillatory rheological test was used to obtain the complex modulus $\left(G^{*}\right)$ and phase angle $(\delta)$ on the dynamic rheological remoter (DSR) at $70^{\circ} \mathrm{C}$.

Micro-characteristics included experiments conducted using ATR-FTIR, FM, and AFM. ATR-FTIR experiments performed on a TENSOR II instrument (Bruker, German) were used to determine the SBS characteristic peak changes, which occurred during the SBS PMA storage process. FM was used to observe the SBS-rich phase distribution, and AFM was used to identify the particle characteristics of the SBS-rich phase. FM was conducted on a DM 2500 system (Leica, German) and AFM was performed using a Dimension Fast Scan system (Bruker, German). Digital imaging technology was used to find the SBS swelling degree and particle characteristic indexes. For FM, the ultraviolet light type used was blue violet light, the magnification times of the ocular glass was $10 \times$, and that of the object glass was $40 \times$. Asphalt films for FM and AFM were obtained by using the heat-casting method. Hot asphalt binder was cast into glass slides to achieve effective flow with a heating temperature of approximately $160^{\circ} \mathrm{C}$. Bitumen-covered sample holders were left overnight at room temperature before testing.

\section{Results}

\subsection{Macro Performance Indexes}

\subsubsection{Conventional Physical Indexes}

Changes in conventional physical indexes as storage time increases are shown in Figure 2. Softening point was typically iso-viscous temperature, penetration was isotemperature viscosity, and ductility was used to identify the low temperature flexibility of SBSPMB.
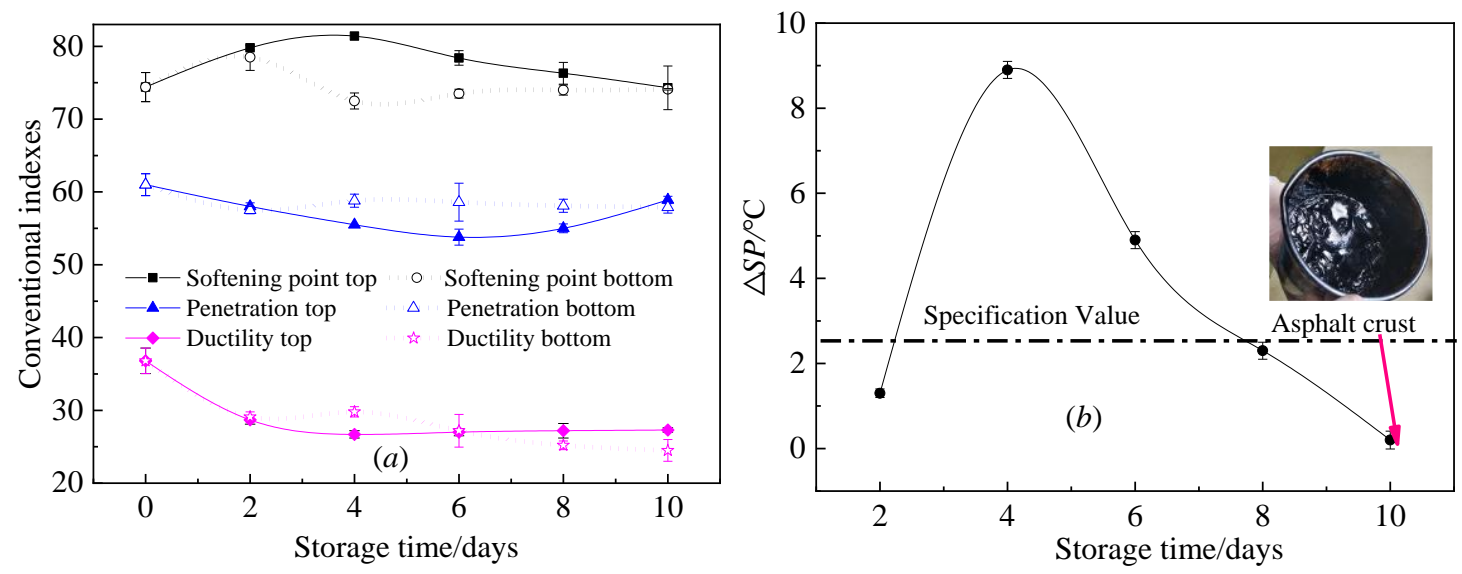

Figure 2. Performance evaluation of SBS modified asphalt based on conventional indexes. The error bar represents the standard deviation of the results of two separate tests. (a) Conventional index at top and bottom part during storage. (b) Softening point difference within $48 \mathrm{~h}$.

As shown in Figure 2a in the top part of SBSPMB, softening point was increased initially and decreased thereafter, penetration was decreased and increased, and peak values ocurred on the 4th and 6th days. Moreover, Figure 2a shows that the softening point 
at the bottom of SBSPMB was increased and then decreased, and the peak happened on the 2nd day; and penetration was decreased and then increased, and the valley value was seen on the 2nd day. Ductility was decreased at all times either in the top or bottom part. Thus, long-term storage results in decreased flexibility at low temperature but increased viscidity at high temperature.

In Figure $2 \mathrm{~b}$, the max value of $\Delta S P_{48}$ was observed on the 4 th day, thereby demonstrating the occurrence of the heaviest segregation or phase separation. However, $\Delta S P_{48}$ was decreased after a 4-day storage. The reason is that all softening points at the top and bottom decreased, indicating a lack of phase separation improvement. On the 8th and 10th days, $\Delta S P_{48}$ satisfied the specification requirement of SBS I-C of China (i.e., below $2.5^{\circ} \mathrm{C}$ ). Asphalt crusts were extremely issues after a 10-day storage, as shown in Figure $2 \mathrm{~b}$. Thus, the attenuation degree of asphalt performance in field storage was not effectively characterized by $\triangle S P_{48}$ alone.

\subsubsection{Rheological Indexes from MSCR}

Accumulated strain, $R_{\mathrm{avg}}$, and $J_{\mathrm{nravg}}$ of three modified asphalts were selected to determine the creep characteristic differences of SBSPMB during long-term thermal storage, as shown in Figure 3.
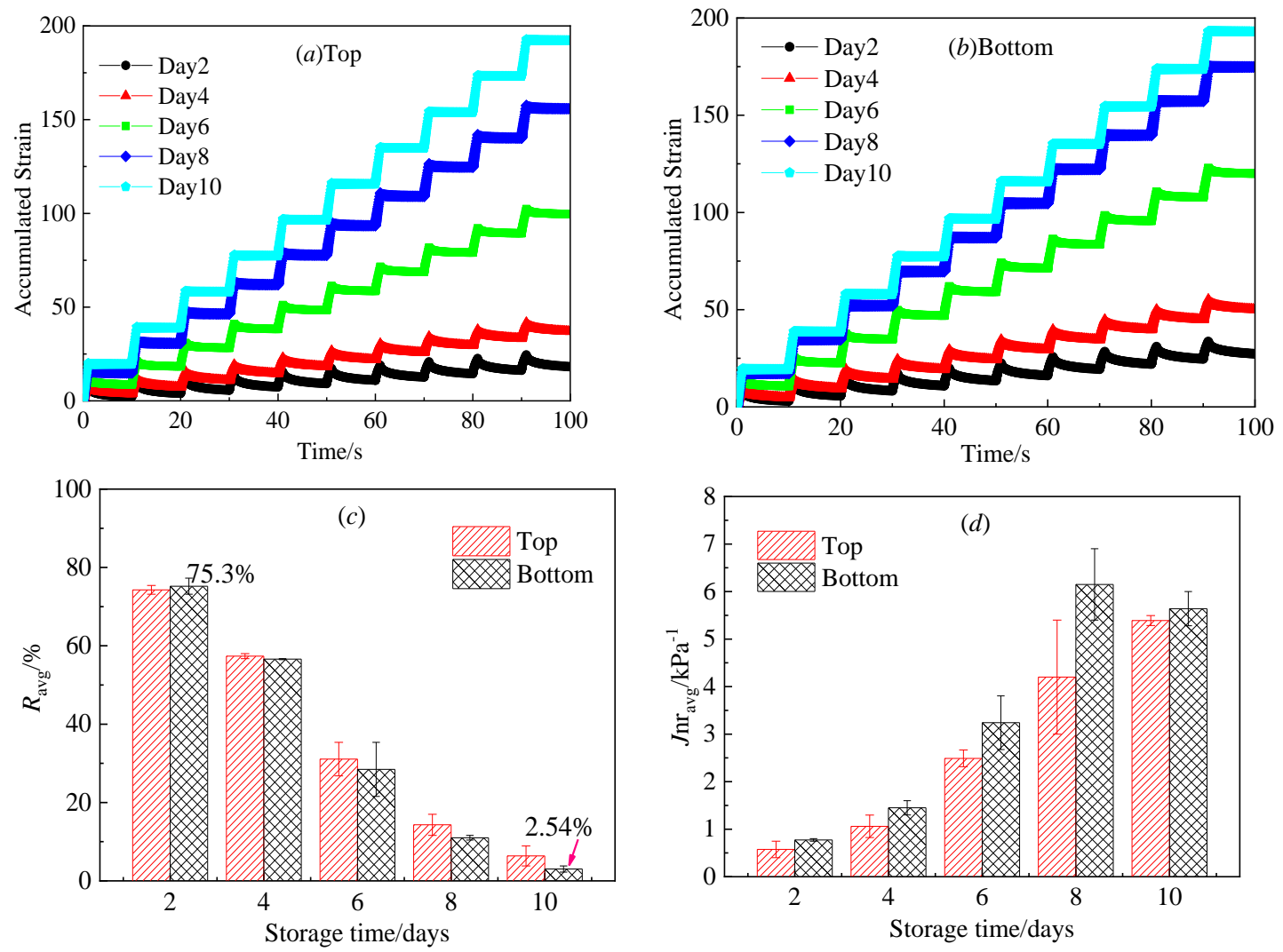

Figure 3. Accumulated strain, $R_{\mathrm{avg}}$, and $J_{\text {nravg }}$ of samples with different storage time. The error bar represents the standard deviation of the results of two separate tests. (a) Accumulated strain at $3.2 \mathrm{kPa}$ at the top of SBSPMB; (b) Accumulated strain at $3.2 \mathrm{kPa}$ at the bottom of SBSPMB; (c) Average recovery rate at $0.1 \mathrm{kPa}$ and $3.2 \mathrm{kPa}$; (d) Average irrecoverable compliance at $0.1 \mathrm{kPa}$ and $3.2 \mathrm{kPa}$.

Equations (1) and (2) were used to obtain the values of $R_{\text {avg }}$ and $J_{\text {nravg, }}$, respectively:

$$
R_{a v g}=\frac{R_{0.1 k P a}+R_{3.2 k P a}}{2}
$$




$$
J n r_{a v g}=\frac{J n r_{0.1 k P a}+J n r_{3.2 k P a}}{2}
$$

where $R_{0.1 \mathrm{kPa}}$ is the recovery rate at $0.1 \mathrm{kPa}, R_{3.2 \mathrm{kPa}}$ is the recovery rate at $3.2 \mathrm{kPa}, R_{\mathrm{avg}}$ is the average value of $R_{0.1 \mathrm{kPa}}$ and $R_{3.2 \mathrm{kPa}}, J_{\mathrm{nr} 0.1 \mathrm{kPa}}$ is the irrecoverable compliance at $0.1 \mathrm{kPa}, J_{\mathrm{nr} 3.2 \mathrm{kPa}}$ is the irrecoverable compliance at $3.2 \mathrm{kPa}$, and $J_{\text {nravg }}$ is the average value of $J_{\mathrm{nr} 0.1 \mathrm{kPa}}$ and $J_{\mathrm{nr} 3.2 \mathrm{kPa}}$. For accumulated strain, the results in Figure $3 \mathrm{a}, \mathrm{b}$ show that the accumulated strain increased with an increase in storage time either at the top or bottom of SBSPMB. A larger accumulated strain demonstrated worse elastic recovery ability at high temperature. The results in Figure 3c,d verify this conclusion. The value of $R$ decreased as storage time increased, while the $J_{n r}$ increased at the top or bottom of SBSPMB. High $R$ and low $J_{n r}$ suggested considerable elasticity at high temperature [31]. Thus, higher $R$ and lower $J_{n r}$ would provide SBSPMB with better anti-rutting property. However, on the 10th day of storage, $R \%$ reduced to $2.54 \%$ and lost $96 \%$ elastic ability, resulting in a significantly high $J_{\mathrm{nr}}$. After a two-day storage, $J_{n r}$ was below $0.5(1 / \mathrm{kPa})$. Thus, long-term hot storage would destroy the three-dimensional network structure, which was proven by the micro-characteristic indexes.

\subsubsection{Rheological Indexes from Small Strain Oscillatory Rheological Test}

Complex modulus $\left(G^{*}\right)$ is an important index to evaluate the load bearing capacity of PMB. Changes in $G^{*}$ at $70^{\circ} \mathrm{C}$ during long-term storage is summarized in Figure 4a. The results showed that $G^{*}$ decreased substantially as storage time increased either at the top or bottom part. A smaller $G^{*}$ provided a lower strength, which was ascribed to the SBS network structure decay and base asphalt aging. In pavement engineering, the ratio of complex modulus to the sine value of the phase angle $\left(G^{*} / \sin \delta\right)$ is called the anti-rutting factor, performing the high temperature in performance grade (PG). $G^{*} / \sin \delta$ variation with storage time is listed in Figure $4 \mathrm{~b}$. The result showed that $G^{*} / \sin \delta$ decreased with an increase in storage time either at the top or bottom part. By contrast, a slightly higher value at the top was observed than the one at the bottom. A larger $G^{*} / \sin \delta$ indicated that this binder could be used in higher air temperature condition. Thus, SBS particle was implied to float up to enhance the modulus and decrease the phase angle of SBSPMB. By contrast, the bottom was completely the opposite. In general, deformation resistance at high temperature of SBSPMB was weakened after long-term storage.
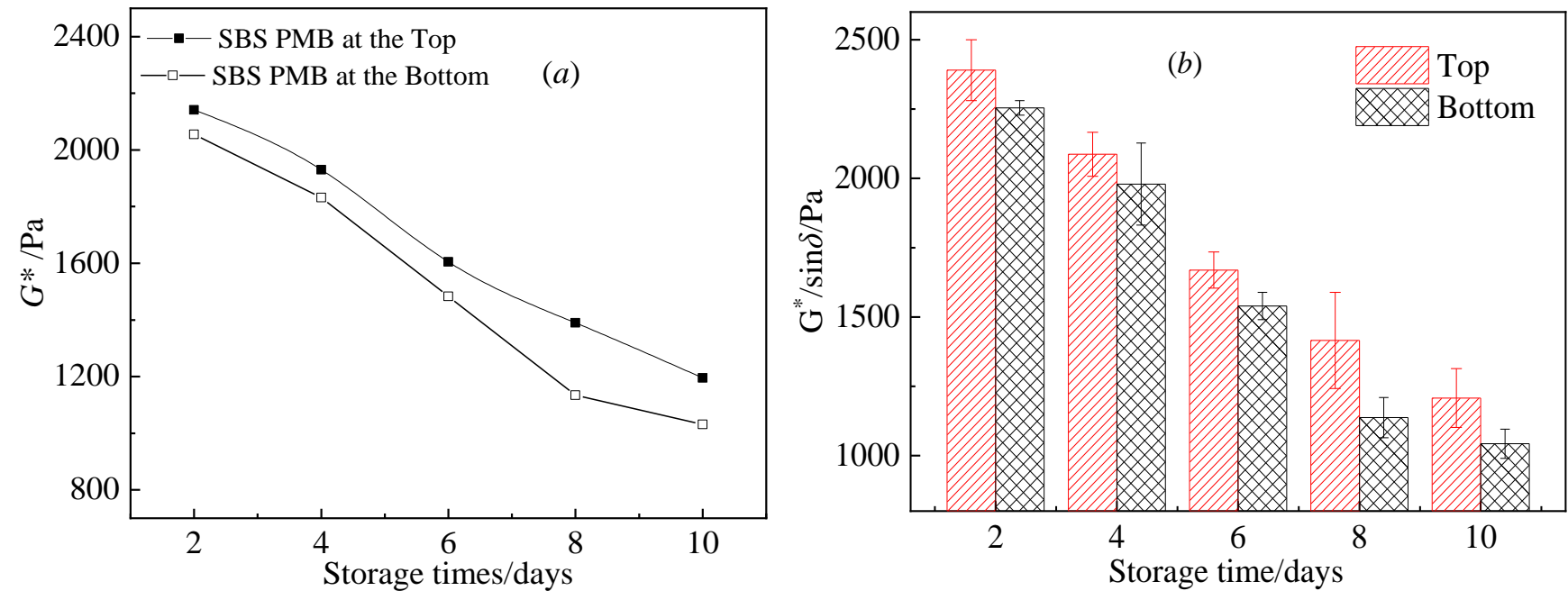

Figure 4. $\mathrm{G}^{*} / \sin \delta$ of samples with different storage time. The error bar represents the standard deviation of the results of two separate tests. (a) is complex modulus. (b) is anti-rutting factor. 


\subsection{Micro Characteristics Indexes}

\subsubsection{Network Structure Strength from Stress-Time Curves}

A rubbery supporting three-dimensional network formed from the SBS phase is the modification nature of SBSPMB. Wehumbura believed that if a modified asphalt exists in a cross-linked network, then the shear stress-time curve from the continuous application of force at a fixed shear rate in strain control mode would show evident peaks and valleys [32]. Thus, network structure strength $(I)$ was proposed to characterize the crosslinking degree of network as follows:

$$
I=\frac{S_{f}}{S_{p}}
$$

where $S_{\mathrm{f}}$ is the peak of the shearing stress, $S_{\mathrm{p}}$ is the flat value of the shearing stress, and all units are in Pa. A large $I$ identified a strong network among the polymer phase that is difficult to destroy by external force. The shearing stress-time curves at the top and bottom of SBSPMB are shown in Figure 5, and the value of $I$ is presented in Figure 6.
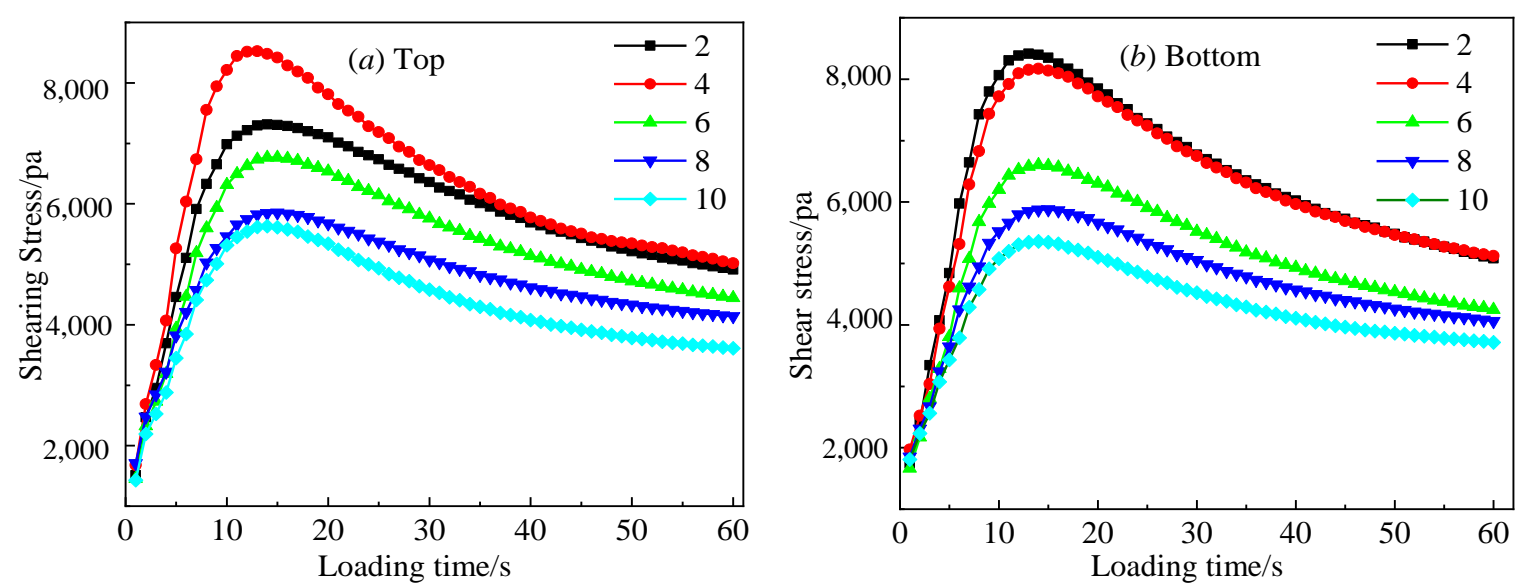

Figure 5. Evaluate of network structure strength. (a) Shearing stress at the top. (b) Shearing stress at the bottom.

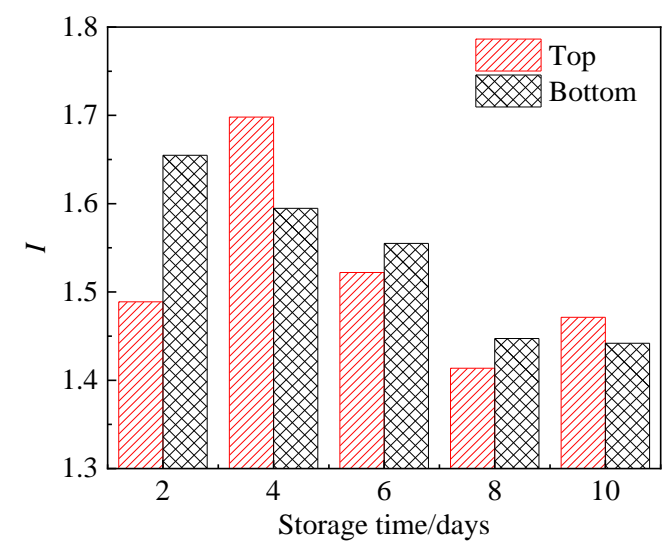

Figure 6. Evaluate of network structure strength.

The results in Figure 5 show that the peak value of the shearing stress-time curve decreased at the bottom with an increase in storage time. For samples at the top, the value at the 2nd storage was smaller than that the 4th day of storage but larger than that at the 6th day of storage. As shown in Figure 6, the value of $I$ increased initially and decreased thereafter at the top, but decreased at all times at the bottom. The low I value at the bottom was mainly attributed to the thermal degradation of SBS. I on the 2nd day was significantly lower than that on the 4 th day at the top of the SBSPMB sample. Macro properties showed that heavy segregation occurred on the 4th day. Thus, the SBS value on the 4 th day was 
considerably higher than that on the 2nd day, indicating a strong network. Moreover, $I$ on the 2nd day was lower than that at the bottom on the 2nd day because the upper part was easily exposed to oxygen, resulting in SBS oxidation. The flowing up of SBS particle during storage was due to its smaller density than asphalt (i.e., approximately $0.9 \mathrm{~g} / \mathrm{cm}^{3}$ ). Thus, factors affecting network strength included SBS degradation, loss of light component, and oxidation of the base asphalt and SBS.

\subsubsection{SBS Swelling Degree from FM}

FM was used to determine the SBS-rich phase distribution characteristics of SBSPMB, as shown in Figure 7. FM images revealed that the SBS swelling degree was calculated on the basis of Equation (4) using digital image technology [33], which indirectly evaluated the compatibility of PMB:

$$
\text { SBS swelling degree }=\frac{A_{P R P}}{A_{\text {Total }}} \times 100 \%
$$

where $A_{\text {PRP }}$ is the area of the SBS-rich phases and $A_{\text {total }}$ is the total area of SBSPMB in the FM images. The original images were processed using MATLAB to convert them into binary images, which only contained two-pixel values (i.e., 0 and 1 ), and to binary black (asphaltene-rich phases) or white (SBS-rich phases) thereafter. $A_{\text {PRP }}$ and $A_{\text {total }}$ were eventually obtained. The SBS swelling degree is illustrated in Figure 8.
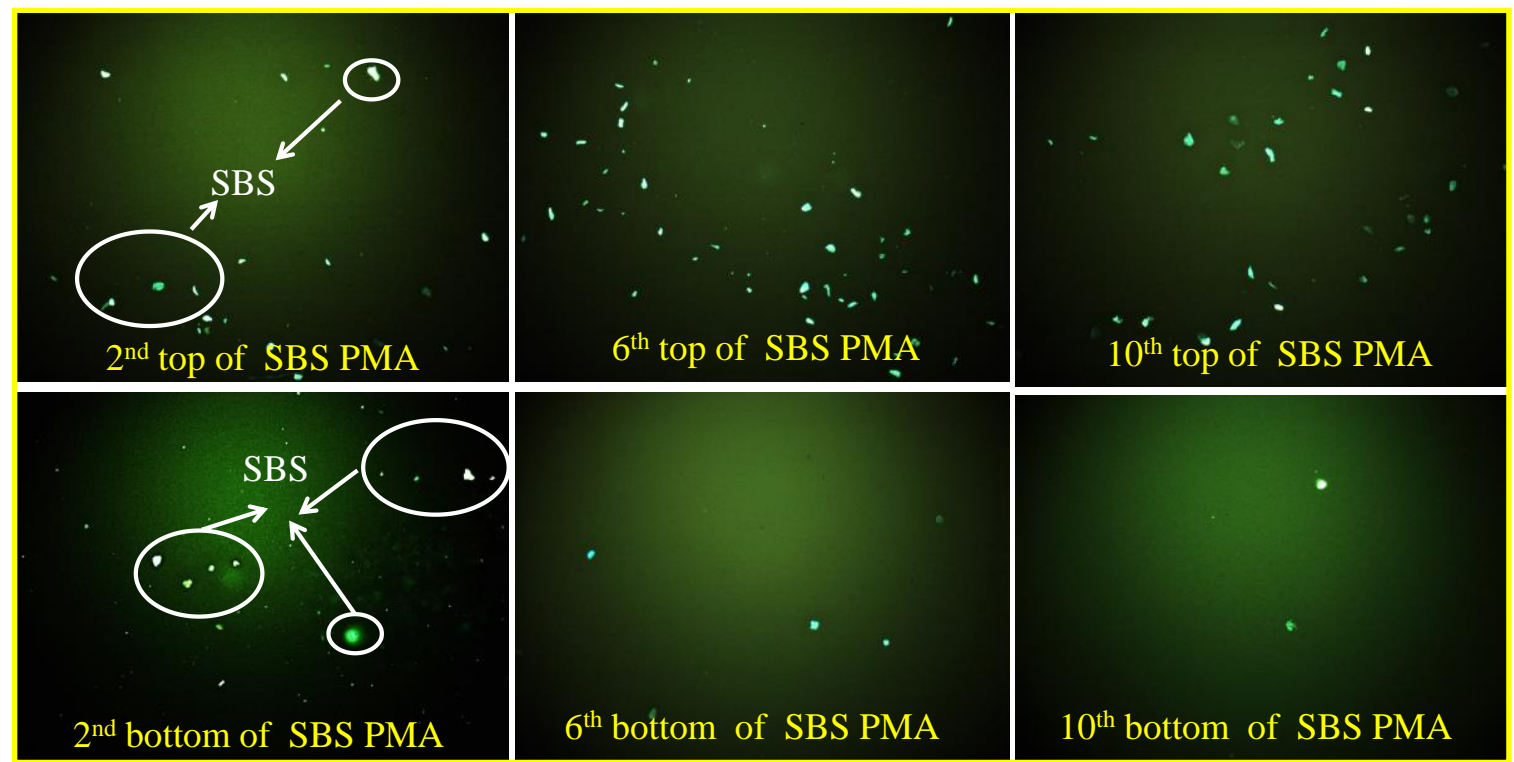

Figure 7. Fluorescence images with different storage time.

The polymer-rich phase of SBSPMB exhibited a higher fluorescence to ultraviolet rays than the bitumen phase; thus, the bright white dots in the FM images were SBS polymers, and the rest was asphalt matrix [34]. As shown in Figure 7, SBS particles increased at the top as storage time increased but decreased at the bottom. The swelling degree of the SBS phase at the top substantially increased on the 4th day and slightly decreased thereafter, as shown in Figure 8. This significant increase was attributed to the upflow of the SBS particles during the first four days. The SBS swelling degree over the range from 4 to 10 days slightly decreased. The main cause of this steady change was the SBS degradation, and a minor consideration may be the SBS phase separation. However, SBS swelling degree at the bottom decreased with an increase in storage time, mainly considering the result of the SBS amount decrease owing to phase separation. 


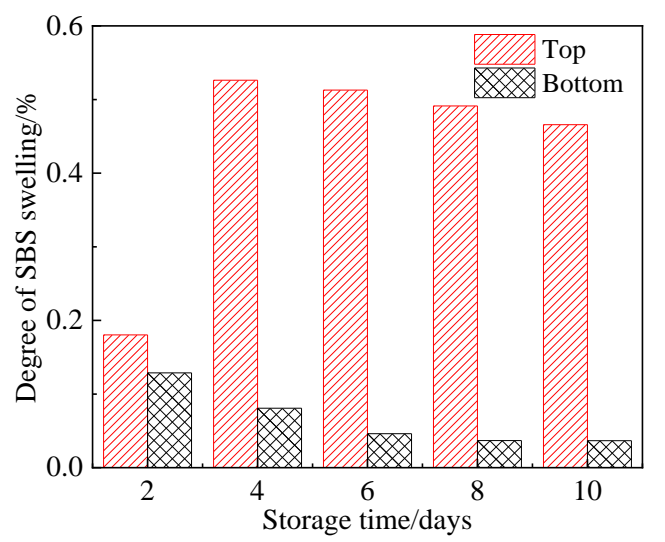

Figure 8. The SBS swelling degree with the increasement of storage time.

\subsubsection{SBS Amount from ATR-FTIR}

Characteristic peaks in the ATR-FTIR spectrum provided the functional group composition in SBSPMB. ATR is an IR sampling technique, which generally enables qualitative or quantitative analysis of samples with minimal or no sample preparation. Thus, this technique could be used for semi-quantitative analysis in pavement engineering. The ATR-FTIR spectra of SBSPMB with different storage time is summarized in Figure 9.
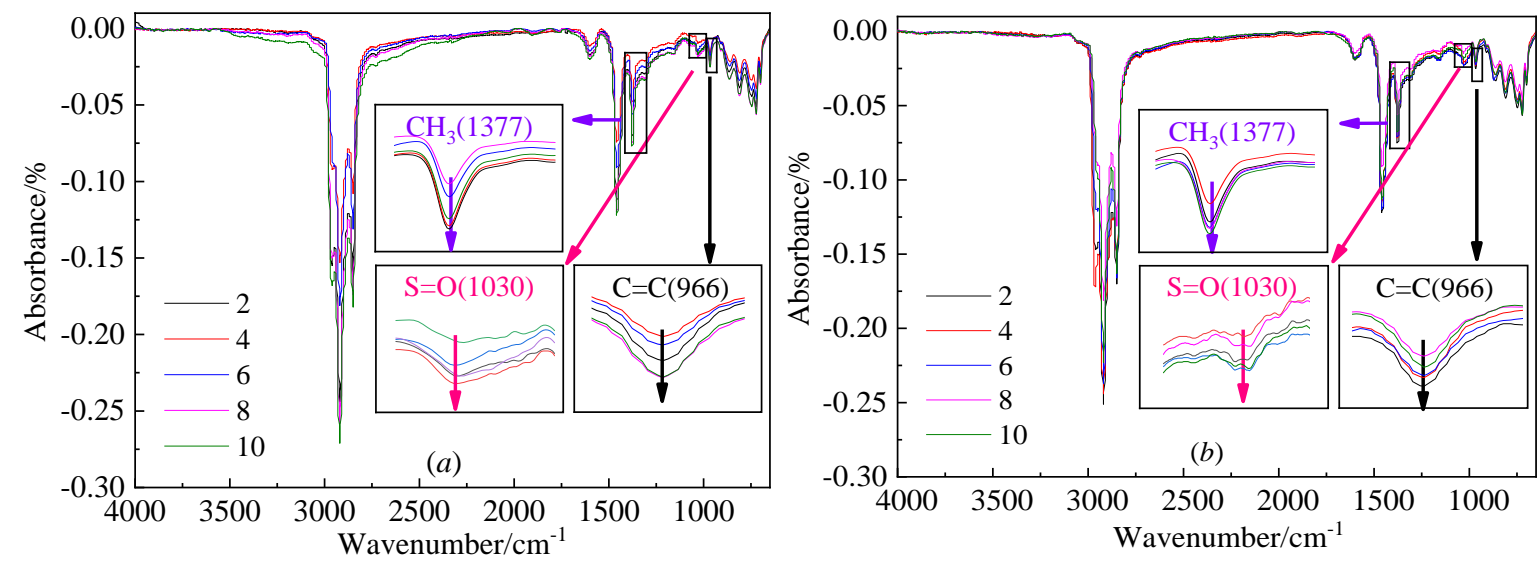

Figure 9. Infrared spectra of different storage time. (a) Infrared spectra at the top; (b) Infrared spectra at the bottom.

As shown in Figure 9, the observed wavenumbers at 2850, 2920, and 1450-1475 $\mathrm{cm}^{-1}$ demonstrate the existence of an aliphatic long chain in saturated hydrocarbon. The characteristic peaks at $1377,1450-1475,2850$, and $2920 \mathrm{~cm}^{-1}$ belonged to the base asphalt. The wavenumber at $1020 \mathrm{~cm}^{-1}$ typically represented asphalt aging degree, and $1377 \mathrm{~cm}^{-1}$ represented the base asphalt [35]. SBS showed characteristic peaks at wavenumbers 699, 760,910 , and $966 \mathrm{~cm}^{-1}$. Peaks at $699 \mathrm{~cm}^{-1}$ and $966 \mathrm{~cm}^{-1}$ belonged to the polystyrene phase of SBS [36]. Meanwhile, $966 \mathrm{~cm}^{-1}$ was the butadiene stretching vibration of SBS, and showed a relatively stronger peak intensity than $699 \mathrm{~cm}^{-1}$. Thus, the characteristic peak index of SBS polymers $\left(A_{\mathrm{SBS}}\right)$ (i.e., $966 \mathrm{~cm}^{-1}$ ) was used to determine the changes in the SBS amount in the asphalt matrix, as shown in Equation (5), where $S_{966}$ and $S_{1377}$ are the peak areas at $966 \mathrm{~cm}^{-1}$ and $1377 \mathrm{~cm}^{-1}$, respectively:

$$
A_{S B S}=\frac{S_{966}}{S_{1377}} \times 100 \%
$$

As shown in Figure 10, the characteristic peaks of SBS polymers at the top increased initially and decreased thereafter, and the peak value was obtained on the 4th day. At the 
bottom, the characteristic peaks of the SBS polymers decreased gradually with storage time. The rule was the same as the macro-performance and other micro-characteristics results. Yan reported that the SBS polymer network could provide a barrier's effect for the oxidation of the actual binder, thereby resulting in improved anti-aging resistant performance when the SBS amount is sufficiently high [32]. Thus, asphalt aging was not considerable apparent as storage time increases, as shown in Figure 9.

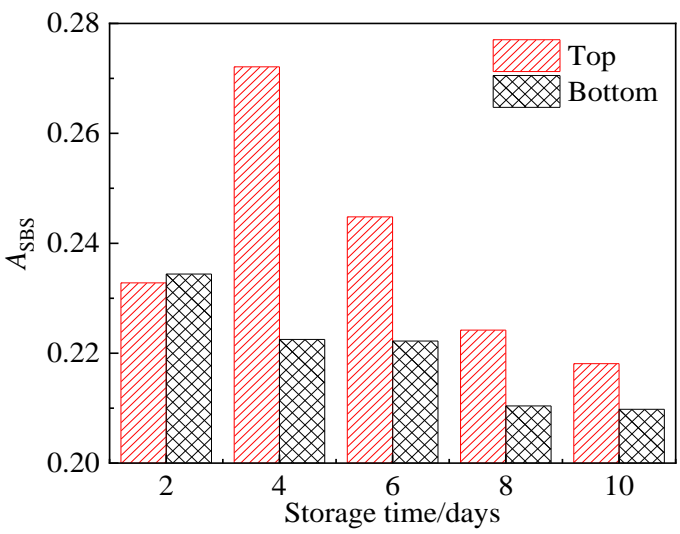

Figure 10. SBS characteristic index $A_{966 / 1377}$

The Beer-Lambert law states that absorbance is proportional to the concentration of a substance at a given wavenumber. Thus, $A_{\mathrm{SBS}}$ was used to determine the SBS amount from the standard curve of SBSPMB using ATR-FTIR. The standard curve of SBSPMB was obtained from the same prepared process and raw materials but different SBS amounts, as discussed in the SBSPMB preparation part. In this case, the amounts were 3\%, 3.5\%, $4 \%, 4.5 \%$, and $5 \%$ based on asphalt quality. The calculation of the SBS amount was similar to that in Wang [37]. The standard curve of the SBS amount for SBSPMB is shown in Figure 11a. The correlation index $R^{2}$ was 0.9933 , showing that the standard curve was effective.
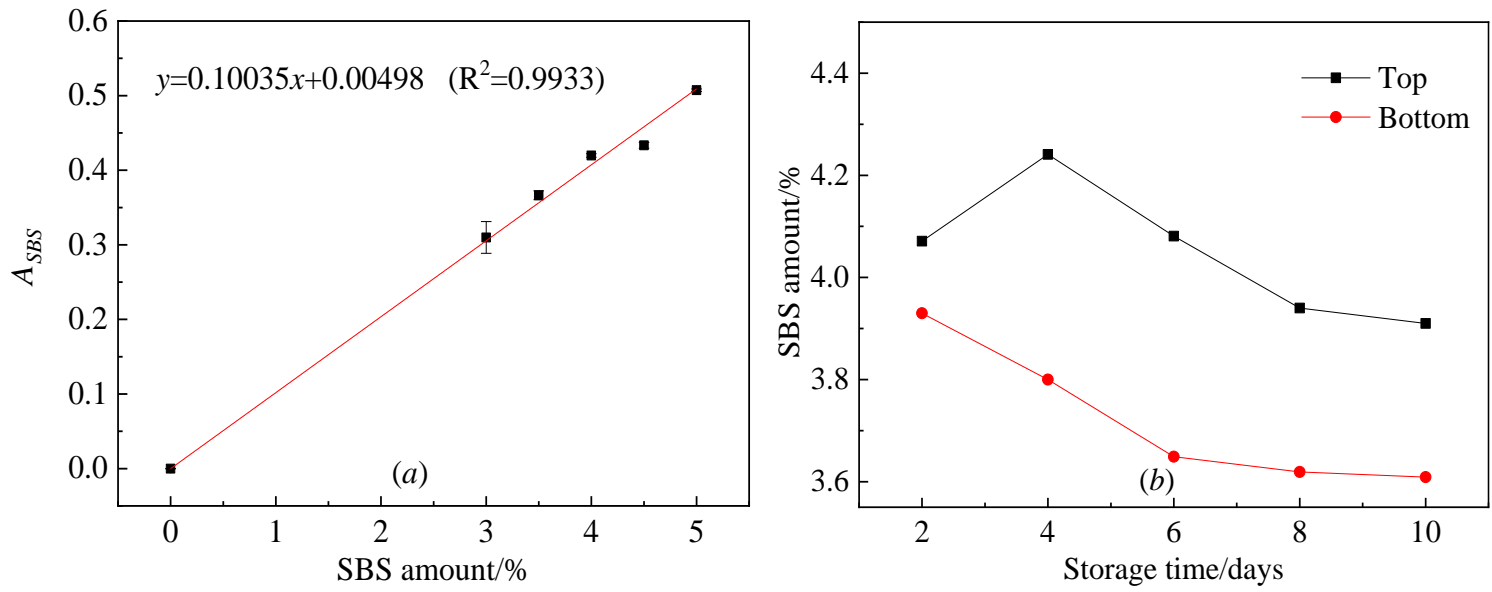

Figure 11. Standard curve of SBS amount for SBSPMB and SBS amount changes as storage time. The error bar represents the standard deviation of the results of five separate tests. (a) Standard curve. (b) The changes of SBS amount.

As shown in Figure 11b, the SBS amount at the top was significantly larger than that at the bottom, demonstrating that SBS flowed up during long-term storage. This result could explain why the 4th day had a large $\triangle S P$, and the upper part dislayed a better macro-performance than the one at the bottom. Meanwhile, the SBS amount at the top increased initially and decreased thereafter as storage time increased, while the value at 
the bottom decreased with an increase in storage time. The reduction of the SBS amount was due to SBS degradation in hot condition, while the increase in SBS amount on the 4th day of the top part was attributed to SBS flowing up.

\subsection{Performance Prediction after Long-Term Storage}

\subsubsection{Grey Relation}

Grey relation is used to explore the relationship between two systems that vary with different objects. Correlation degree is used to measure the degree of similarity or difference of development trend between the two. This study used grey correlation degree to identify the most representative index of the SBS amount. The correlation degree of the macro-micro indexes referenced as SBS amount are shown in Figure 12.
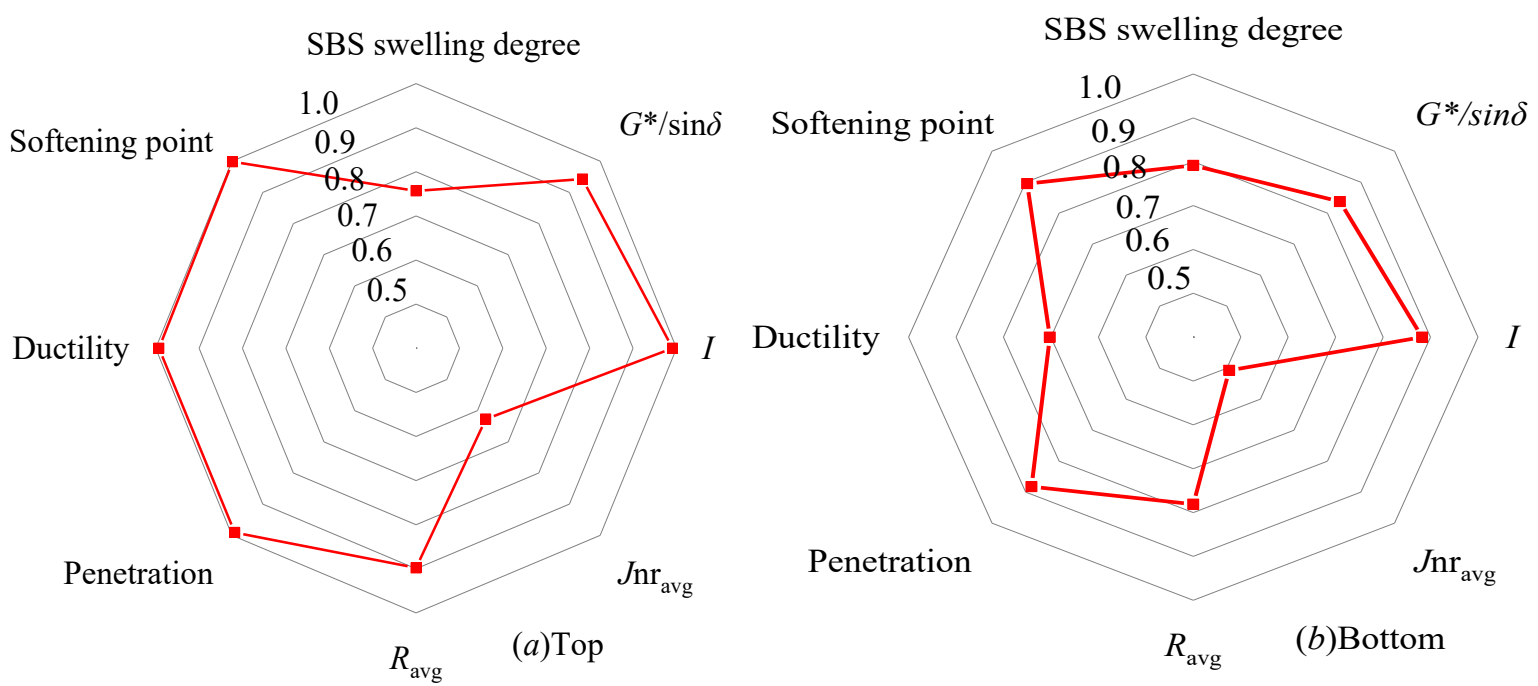

Figure 12. Grey correlation degree between evaluation indexes of top and bottom samples and SBS content. (a) Correlation degree of top sample index. (b) Correlation degree of bottom sample index.

For the samples at the top part in Figure 12a, the softening point, ductility, penetration, $I, R_{\mathrm{avg}}$, and $G^{*} / \sin \delta$ showed a grey correlation degree near 1.0, implying they had a closed relationship with SBS amount. However, the grey correlation degree among penetration, softening point, $I, R_{\mathrm{avg}}, G^{*} / \sin \delta$, and SBS amount at the bottom are above 0.8 . However, indexes at the bottom provided smaller grey correlation degree than that at the top. SBS swelling degree and $J_{\text {nravg }}$ showed slightly smaller correlation with SBS amount. For segregation, the phase separation degrees were determined using Equation (6):

$$
\text { Degree of separation }\left(\Delta_{\mathrm{i}}\right)=\left|\frac{\text { Top parameters }- \text { Bottom parameters }}{\text { Average of the top and bottom parameters }}\right| \times 100 \%
$$

The grey correlation degree between the segregation degree based on different indexes and SBS amount is shown in Figure 13. Meanwhile, $\Delta S P_{48}$ showed a superior relationship with SBS amount either at the top or bottom part, yet it was not accurate diagnotic of the performance decay during long-term storage though satisfied specification requirement. $G^{*} / \sin \delta$ has a high grey correlation degree at the top/bottom part and segregation degree. On a micro-scale, $I$ and SBS swelling degree hold a correlation degree above 0.7 , although $I$ has a higher correlation degree at the top and bottom with its SBS amount. Thus, the network structure strength $I$ would be a potential indicator to describe the SBS phase separation during storage. 


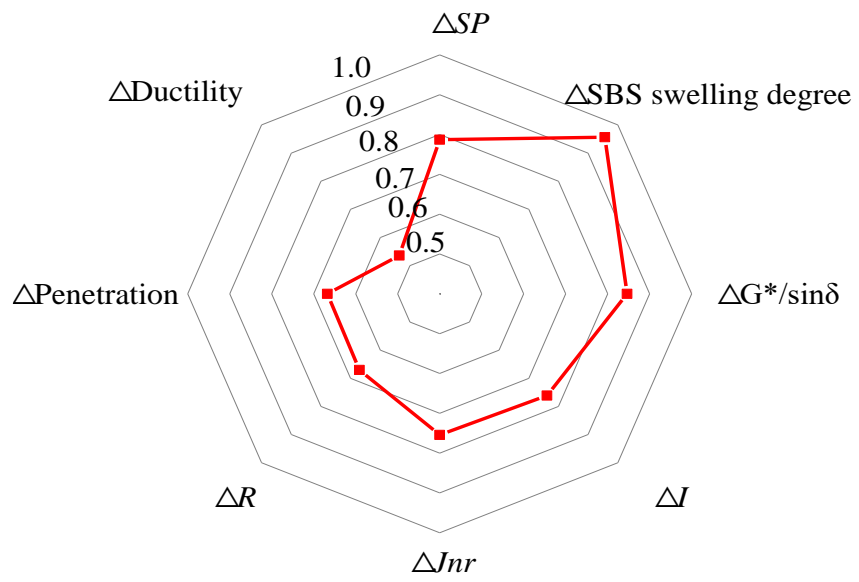

Figure 13. The grey correlation degree between SBS amount and segregation degree based on different indexes.

\subsubsection{PLS Regression Model}

PLS is a multivariate statistical linear regression technique based on estimated latent variables, which extracts the relationships between dependent and independent variables [37]. In this study, the purpose of PLS regression is to build a linear model to predict the rheological properties and micro-characteristic index based on conventional physical indexes, including penetration, ductility, and softening point during storage. The reason is that conventional physical indexes are easily obtained in all testing organizations.

The prediction models are presented in Figure 14. The highest prediction accuracy was $G^{*} / \sin \delta$ and its $R^{2}$ was 0.9111 , as shown in Figure $14 \mathrm{~b}$. The second was $R_{\text {avg }}$ and its $R^{2}$ was 0.8828 , as presented in Figure 14c. The prediction accuracy of the SBS amount and $J_{\text {nrave were }} 0.8540$ and 0.8390 , respectively, as shown in Figure $14 \mathrm{a}, \mathrm{d}$, respectively. However, the prediction accuracy of $I$ and SBS swelling degree was below 0.8 , demonstrating a lack of relevance with the conventional physical indexes. Conventional physical indexes were not identifying network strength and the changes of the SBS swelling degree during storage. Thus, segregation based on $\Delta S P_{48}$ only was not suitable to determine the macro-performance and micro-characteristics changes. The current research suggested that $G^{*} / \sin \delta$ and I may be superior indexes to monitor the macro- and micro-changes of SBSPMB with storage time. 

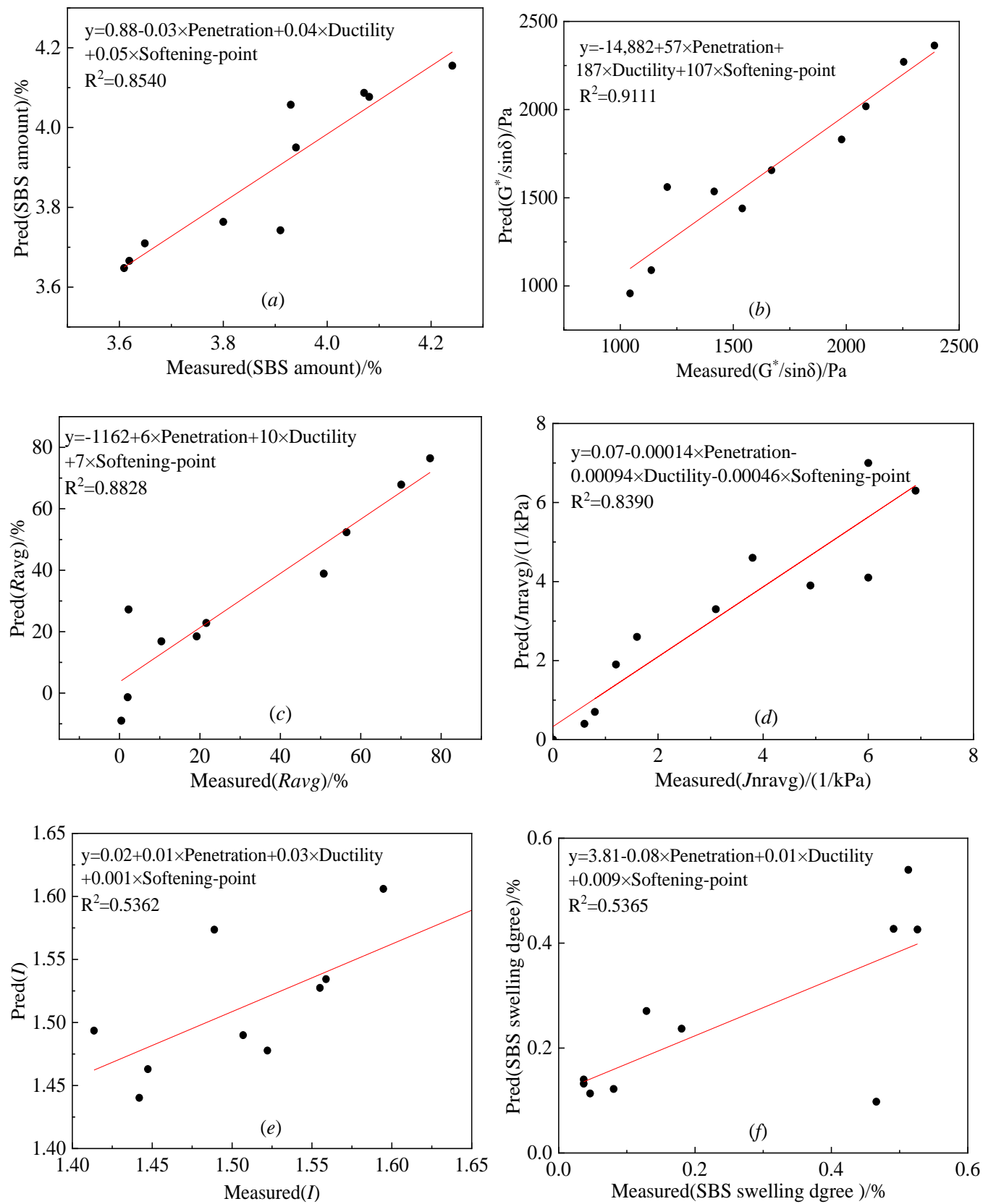

Figure 14. Measured and predicted values of indicators. (a) Prediction of SBS amount. (b) Prediction of $G^{*} / \sin \delta$. (c) Prediction of $R_{\text {avg. }}$ (d) Prediction of $J_{\text {nravg. }}$ (e) Prediction of $I$. (f) Prediction of SBS swelling degree.

\section{Conclusions}

The elusive thermal storage stability of SBSPMB has attracted wide attention during over half a century of intensive research. However, the existing softening point difference evaluation index within $48 \mathrm{~h}$ could not distinguish between phase separation and performance decay during thermal storage. Thus, this research investigated macro performance, micro-characteristic indexes, and their correlation. Lastly, this study provided prediction models based on conventional physical indexes using PLS regression.

The results from the macro performance indexes indicated that $\Delta S P_{48}$ increased initially and decreased thereafter to even below $2.5^{\circ} \mathrm{C}$ after an 8-day storage. The largest $\triangle S P$ was observed on the 4 th day of storage. Ductility either at the top or bottom decreased with an increase in storage time. Penetration either at the top or bottom slightly decreased initially and increased thereafter. For rheological indexes, Jnr increased, while $R$ and 
$G^{*} / \sin \delta$ decreased with an increase in storage time. The results implied a worse hightemperature performance after long-term storage, and the values of the bottom samples decayed more substantially than those of the top owing to SBS flowing up.

The results from the micro-characteristic indexes revealed that the network structure strengths were reduced with an increase in storage time either at the top or bottom, except the one at the top on the second day. The top on the first two days can easily contact oxygen, thereby leading SBS to undergo oxidation although the swelling degree and SBS amount was not changed substantially. For the SBS swelling degree, the values of the top were significantly higher than those of the bottom. Meanwhile, the top showed higher SBS amount than that of the bottom, demonstrating SBS flowing up. Phase separation of SBS mainly occurred after a 4-day storage, and the decay of performance for SBSPMB was attributed to SBS degradation and base asphalt aging.

The grey correlation degree was used to find the relationship between SBS amount and other macro- and micro-indexes. The results showed that softening point, penetration, $I, R_{\mathrm{avg}}$, and $G^{*} / \sin \delta$ either at the top or bottom part, as well as their segregation degree, showed a close relationship with SBS amount. Penetration, ductility, and softening point were used to build a prediction model for rheological properties after long-term storage using PLS. The model can predict $I, R, J n r, G^{*} / \sin \delta$, and SBS amount effectively. $G^{*} / \sin \delta$ and $I$ at the top or bottom storage location of SBSPMB have high coefficients with SBS amount. Thus, they were better in evaluating the phase separation of SBSPMB during thermal storage. This study will be beneficial in obtaining an improved understanding of the durability of PMB and controlling its quality in the field.

Author Contributions: Writing—original draft preparation, P.W. and X.-Y.L.; writing-review and editing, P.W. and H.-R.W.; visualization, R.-B.R.; supervision, L.-Z.W.; project administration, R.B.R.; funding acquisition, P.W. All authors have read and agreed to the published version of the manuscript.

Funding: The research was funded by National Natural Science Foundation of China (grant no. 51808322), Key Program of Shandong Provincial Natural Science (grant no. ZR2020KE007), and Shandong Provincial Young Scholars Innovative Research Team Development Program in Colleges and Universities (grant no. 2019KJG004).

Institutional Review Board Statement: Ethical review and approval were waived for this study, due to the studies not involving humans or animals.

Informed Consent Statement: Informed consent was obtained from all subjects involved in the study.

Data Availability Statement: The data used to support the findings of this study are included within the article.

Acknowledgments: This study was completed at the School of Transportation Engineering in Shandong Jianzhu University.

Conflicts of Interest: The authors declare no conflict of interest.

\section{References}

1. Chen, J.S.; Liao, M.C.; Shiah, M.S. Asphalt modified by styrene-butadiene-styrene triblock copolymer: Morphology and model. J. Mater. Civ. Eng. 2002, 14, 224-229. [CrossRef]

2. Ali, M.B.; Hamad, A.A.; Abdulrahman, S.A. Comparison of rheological properties for polymer modified asphalt produced in Riyadh. Int. J. Civ. Environ. Struct. Constr. Archit. Eng. 2016, 10, 197-201.

3. Zhao, Y.J.; Jiang, J.W.; Dai, Y.Q.; Lan, Z.; Ni, F.J. Thermal property evaluation of porous asphalt concrete based on heterogeneous meso-structure finite element simulation. Appl. Sci. 2020, 10, 1671. [CrossRef]

4. Dai, Y.Q.; Jiang, J.W.; Gu, X.Y.; Zhao, Y.J.; Ni, F.J. Sustainable urban street comprising permeable pavement and bioretention facilities: A practice. Sustainability 2020, 12, 8288. [CrossRef]

5. Zhu, J.; Birgisson, B.; Kringos, N. Polymer modification of bitumen: Advances and challenges. Eur. Polym. J. 2014, 54, 18-38. [CrossRef]

6. Xia, T.; Xu, J.; Huang, T. Viscoelastic phase behavior in sbs modified bitumen studied by morphology evolution and viscoelasticity change. Constr. Build. Mater. 2016, 105, 589-594. [CrossRef] 
7. Zhu, J.; Kringos, N. Towards the development of a viscoelastic model for phase separation in polymer-modified bitumen. Road Mater. Pavement. 2015, 16, 39-49. [CrossRef]

8. Lu, X.; Isacsson, U.; Ekblad, J. Phase separation of SBS polymer modified bitumens. J. Mater. Civ. Eng. 1999, 11, 51-57. [CrossRef]

9. Liu, Y.; Zhang, J.; Jiang, Y. Investigation of secondary phase separation and mechanical properties of epoxy SBS-modified asphalts. Constr. Build. Mater. 2018, 165, 163-172. [CrossRef]

10. Leng, Z.; Tan, Z.; Yu, H.; Guo, J. Improvement of storage stability of SBS-modified asphalt with nanoclay using a new mixing method. Road Mater. Pavement 2019, 20, 1601-1614. [CrossRef]

11. Nciri, N.; Kim, N.; Cho, N. New insights into the effects of styrene-butadiene-styrene polymer modifier on the structure, properties, and performance of asphalt binder: The case of ap-5 asphalt and solvent deasphalting pitch. Mater. Chem Phys. 2017, 193, 477-495. [CrossRef]

12. Li, Y.; Li, L.; Zhang, Y. Improving the aging resistance of styrene-butadiene-styrene tri-block copolymer and application in polymer-modified asphalt. J. Appl. Polym. Sci. 2010, 116, 754-761. [CrossRef]

13. Zhu, J.; Lu, X.; Kringos, N. Experimental investigation on storage stability and phase separation behaviour of polymer-modified bitumen. Int. J. Pavement Eng. 2016, 19, 832-841. [CrossRef]

14. Ali, M.B.; Suhana, K.; Nor, H.R.S.; Mohamed, R.K. Optimization of mixing time for polymer modified asphalt. Mater. Sci. Eng. 2019, 512, 012030.

15. Fu, H.Y.; Xie, L.D.; Dou, D.Y.; Li, L.F.; Yu, M.; Side, Y. Storage stability and compatibility of asphalt binder modified by SBS graft copolymer. Constr. Build. Mater. 2007, 21, 1528-1533. [CrossRef]

16. Ren, S.S.; Liu, X.Y.; Fan, W.Y.; Wang, H.P.; Sandra, E. Rheological properties, compatibility, and storage stability of SBS latexmodified asphalt. Materials 2019, 12, 3683. [CrossRef]

17. Zhang, F.; Yu, J.Y.; Wu, S.P. Effect of ageing on rheological properties of storage-stable SBS/sulfur-modified asphalt. J. Hazard. Mater. 2010, 182, 507-517. [CrossRef]

18. Liang, M.; Xin, X.; Fan, W. Effects of polymerized sulfur on rheological properties, morphology and stability of SBS modified asphalt. Constr. Build. Mater. 2017, 150, 860-871. [CrossRef]

19. Carcer, I.A.; De Masegosa, R.M.; Vinas, M.T. Storage stability of SBS/sulfur modified bitumens at high temperature: Influence of bitumen composition and structure. Constr. Build. Mater. 2014, 52, 245-252. [CrossRef]

20. Larsen, D.O.; Alessandrini, J.L.; Bosch, A.; Cortizo, M.S. Micro-structural and rheological characteristics of SBS-asphalt blends during their manufacturing. Constr. Build. Mater. 2009, 23, 2769-2774. [CrossRef]

21. Lu, H.; Ye, F.; Yuan, J.; Yin, W. Properties comparison and mechanism analysis of naphthenic oil/SBS and nano-mmt/SBS modified asphalt. Constr. Build. Mater. 2018, 187, 1147-1157. [CrossRef]

22. Tarsi, G.; Varveri, A.; Lantieril, C.; Scarpas, A. Effects of different aging methods on chemical and rheological properties of bitumen. J. Mater. Civ. Eng. 2018, 30, 4018009-4018017. [CrossRef]

23. Zhang, D.; Zhang, H.; Zhu, C.; Shi, C. Synergetic effect of multi-dimensional nanomaterials for anti-aging properties of SBS modified bitumen. Constr. Build. Mater. 2017, 144, 423-431. [CrossRef]

24. Martínez-Anzures, J.D.; Zapién-Castillo, S.; Salazar-Cruz, B.A. Preparation and properties of modified asphalt using branch SBS/nanoclay nanocomposite as a modifier. Road Mater. Pavement 2019, 20, 1275-1290. [CrossRef]

25. Goli, A.; Ziari, H.; Amini, A. Influence of carbon nanotubes on performance properties and storage stability of SBS modified asphalt binders. J. Mater. Civ. Eng. 2017, 29, 4017070. [CrossRef]

26. Liang, M.; Liang, P.; Fan, W. Thermo-rheological behavior and compatibility of modified asphalt with various styrene-butadiene structures in SBS copolymers. Mater. Des. 2015, 88, 177-185. [CrossRef]

27. Zhu, J.; Lu, X.; Balieu, R.; Kringos, N. Modelling and numerical simulation of phase separation in polymer modified bitumen by phase-field method. Mater. Des. 2016, 107, 322-332. [CrossRef]

28. Liang, M.; Xin, X.; Fan, W.; Wang, H.; Sun, W. Phase field simulation and microscopic observation of phase separation and thermal stability of polymer modified asphalt. Constr. Build. Mater. 2019, 204, 132-143. [CrossRef]

29. Singh, S.K.; Kumar, Y.; Ravindranath, S.S. Thermal degradation of SBS in bitumen during storage: Influence of temperature, SBS concentration, polymer type and base bitumen. Polym. Degrad. Stab. 2018, 147, 64-75. [CrossRef]

30. Masson, F.; Collins, P.; Robertson, G.; Woods, J.R.; Margeson, J. Thermodynamics, phase diagrams, and stability of bitumen-polymer blends. Energy Fuel 2003, 17, 714-724. [CrossRef]

31. Yan, C.; Huang, W.; Lin, P.; Zhang, Y.; Lv, Q. Chemical and rheological evaluation of aging properties of high content SBS polymer modified asphalt. Fuel 2019, 252, 417-426. [CrossRef]

32. Wekumbura, C.; Stastna, J.; Zanzotto, L. Destruction and recovery of internal structure in polymer-modified asphalts. J. Mater. Civ. Eng. 2007, 19, 227-232. [CrossRef]

33. Sengoz, B.; Isikyakar, G. Analysis of styrene-butadiene-styrene polymer modified bitumen using fluorescent microscopy and conventional test methods. J. Hazard. Mater. 2008, 150, 424-432. [CrossRef]

34. Sugano, M.; Iwabuchi, Y.; Watanabe, T. Relations between thermal degradations of SBS copolymer and asphalt substrate in polymer modified asphalt. Clean Technol. Environ. 2010, 12, 653-659. [CrossRef]

35. Wang, P.; Dong, Z.; Tan, Y.; Liu, Z. Anti-ageing properties of styrene-butadiene-styrene copolymer-modified asphalt combined with multi-walled carbon nanotubes. Road Mater. Pavement Design. 2016, 18, 533-549. [CrossRef] 
36. Wang, P.; Shil, F.; Liu, X. Role of aliphatic chain characteristics on the anti-cracking properties of polymer-modified asphalt at low temperatures. Polymers 2019, 11, 31817766. [CrossRef] [PubMed]

37. Wang, K.; Yuan, Y.; Han, S.; Yang, Y. Application of FTIR spectroscopy with solvent-cast film and PLS regression for the quantification of SBS content in modified asphalt. Int. J. Pavement Eng. 2019, 20, 1336-1341. [CrossRef] 